\title{
A RESONANT TRANSFORMER FOR HIGH VOLTAGE TESTING OF GENERATOR STATORS
}

\author{
Pat Bodger* and Wade Enright** \\ *Department of Electrical and Computer Engineering \\ University of Canterbury, Christchurch \\ **Viva Technical Solutions, Christchurch
}

\begin{abstract}
:
A partial core transformer has been designed such that its magnetising reactance has been matched to a generator stator insulation capacitance. The reactive current drawn by the stator insulation is provided by the transformer magnetisation This means that the supply only has to provide the real power losses of the transformer and in practice any mismatch between the magnetisation current and the stator capacitance. A high voltage inductor was designed and used in the testing of a generator at a New Zealand power station. It supplied $115 \mathrm{kvar}$ of reactive power compensation at $23 \mathrm{kV}$. The inductor was turned into a resonant transformer by the addition of a low voltage primary. A laboratory test showed that the required high voltage of $23 \mathrm{kV}$ could be obtained from energising the primary at $285 \mathrm{~V}$ at $60 \mathrm{~A}$ or at a rating of about $1 / 7$ th the load. A further resonant transformer was then designed for a $334 \mathrm{kvar}$ capacitor load to test generator stators at $31.5 \mathrm{kV}$. This transformer was supplied from a nominal $400 \mathrm{~V}$ supply and gave a gain in $\mathrm{kVA}$ of 16 . The transformer has a finished weight of approximately $300 \mathrm{~kg}$.
\end{abstract}

\section{INTRODUCTION}

Generator stators require high voltage testing of their insulation as part of their acceptance before being put into service. Traditionally this has involved the application of a high dc voltage. The equipment required to do this is relatively small and portable, as the insulation charging current can be kept small as the voltage is ramped up to its required value.

However, more and more utility owners are calling for over-voltage acceptance tests to be made at mains frequency. These tests may be of the order of $2-3$ times rated voltage for 1 minute. Under ac conditions, the amount of current required by the insulation capacitance depends on the physical dimensions of the stator winding. It may not be insignificant. To supply this current directly from a power supply can involve a capacity greater than what is available from local services, such that dedicated test units with their own generator sets may be necessary. These can be physically very large and heavy, with consequent high test costs. Series [1] and parallel [2] resonant test sets are available which reduce the VA requirement of the supply. They use conventional full core transformers to supply the resonant load.
An alternative test apparatus has been designed around a partial core transformer concept [3]. The transformer has laminated core material only in the space enclosed by the windings. There are no limbs and yokes as found in conventional full core transformers. One of the characteristics of these transformers is that they have relatively low magnetising reactance. Through judicious design, this reactance can be matched to a generator stator capacitance such that the reactive current of the insulation is provided by the magnetisation. This is essentially setting up a parallel resonance between these two components. This means that the supply only has to provide the real power losses of the transformer and in practice any mismatch between the magnetisation current and the stator capacitance. The primary winding can thus be downsized to conduct only this supply current.

\section{RESONANT INDUCTOR}

To test the partial core resonant concept in practise, a high voltage inductor was designed and used in the testing of a $50 \mathrm{~Hz}, 11 \mathrm{kV}, 40 \mathrm{MW}$ generator at the Matahina power station in New Zealand. The design specification called for a $50 \mathrm{~Hz}$ ac test voltage of $23 \mathrm{kV}$ for 1 minute. The stator capacitance was estimated to be between 0.217 and $0.422 \mu \mathrm{F}$ per phase, although at the time of designing, these were not firm. These 
capacitance values equate to reactances of approximately 14,700 and 7,500 ohms respectively. In designing an inductor to suit these specifications, a combination of core and winding size needs to be estimated such that the required performance is achieved within the constraints of permissible flux and current densities. Consideration must also be given to the voltage per turn and voltage per layer of the winding which affect the selection of insulation used in the inductor. A core size of $715 \mathrm{~mm}$ length and $125 \mathrm{~mm}$ diameter was determined, and the copper winding wire was $1 \mathrm{~mm}$ in diameter. These values were obtained through a process of design/performance evaluation using a computer program created for the purpose [2]. These selections may not be optimum, and the design is non-unique, but they were arrived at through observation of predicted performance and experience.

As the inductor was physically larger than anything designed before, and that modelling is inherently inaccurate, caution was applied to the design by selecting a total of 15 layers of $1 \mathrm{~mm}$ diameter wire. The number of turns was 10,170. Taps were made from layer 9. This gave a range of calculated magnetising reactances from about 4,700 to 18,600 ohms. Each layer was insulated with $0.35 \mathrm{~mm}$ thick Nomex, which is rated for a breakdown voltage of about $18 \mathrm{kV}$. The neutral end of the winding was placed next to the core.

In preliminary tests, corona discharge was detected in layer 14 where a join in the winding wire was made. The outer 2 layers were thus discarded, leaving a 13 layer, 8,814 turn winding with a maximum calculated reactance of approximately 14,000 ohms. The measured values of reactance ranged from about 4,700 to $11,900 \mathrm{ohms}$ for 9 to 13 layers respectively, the values being somewhat smaller than the calculation. It was also observed that the amount of corona was affected by the proximity of the inductor to the ground, because of the asymmetric electric field set up in coupling to the ground. The inductor was raised on insulated upstands to reduce this.

The inductor was subjected to a $30 \mathrm{kV}$ voltage applied for 3 minutes to prove its insulation integrity. On site, as shown in Figure 1, the inductor was used on the tap at layer 9. It drew $4.9 \mathrm{~A}$ at $23 \mathrm{kV}$ for a rating of $113 \mathrm{kvar}$. The generator stator insulation was measured at $0.56 \mu \mathrm{F}$, corresponding to about $5700 \mathrm{ohms}$. This was almost twice the design value. Fortunately, the flexibility and relative conservatism in the design allowed an appropriate tap selection to accommodate the actual load. Under test, the stator insulation drew $4.1 \mathrm{~A}$ at $23 \mathrm{kV}$, implying some over-compensation of reactive current by the inductor. Nevertheless, the supply current was reduced to $0.75 \mathrm{~A}$, significantly below that which would have been necessary without the inductor in circuit. Thus a VA gain of 5.5 from the supply to the load was obtained. This allowed the use of a lower VA rating $\mathrm{HV}$ test supply transformer, supply variac, with smaller station supply and protection considerations.

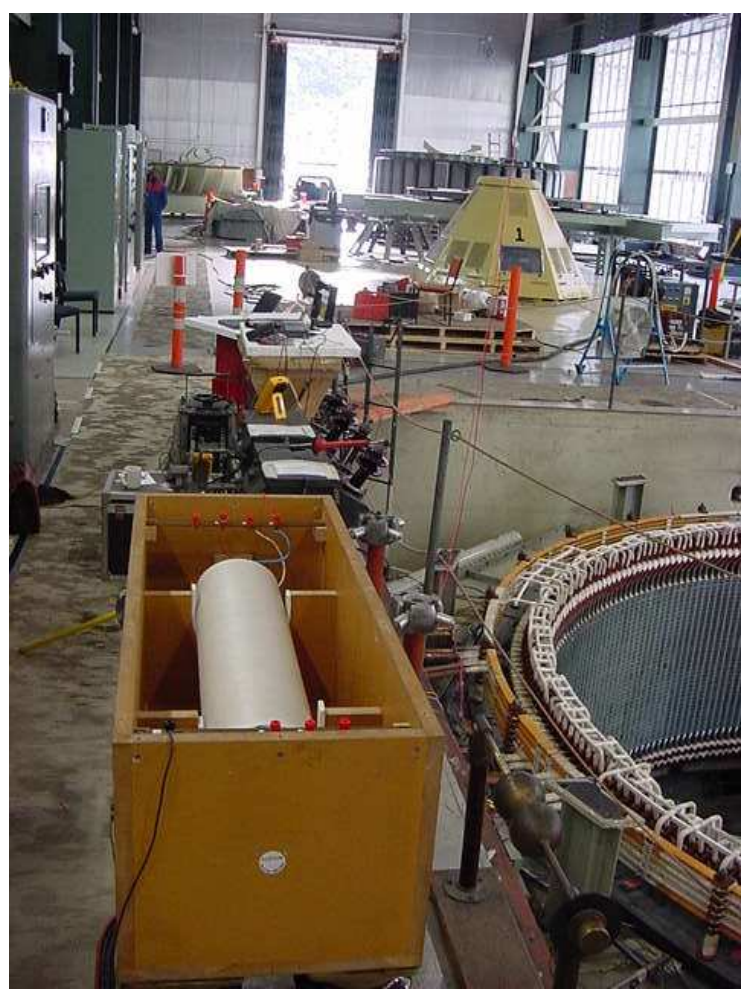

Fig. 1 Resonant inductor in use at Matahina

\section{RESONANT TRANSFORMER}

There was still some difficulty in providing an appropriate test transformer as the high voltage supply. This was a limit of what was available in New Zealand. An alternative presented itself in that the partial core compensating inductor concept could be modified to be its own transformer.

For the tests on the Matahina stator, there was a degree of over-compensation of the capacitance by the stator. It would have been more appropriate to use 10 layers for the inductor winding. For design purposes, the inductor was altered by placing a LV winding around the HV winding. This was made from a single layer of 68 turns of 5.0 by $2.5 \mathrm{~mm}$ rectangular aluminium wire. The wire size was selected more by what would best cover the primary to reduce leakage, than for current density optimisation, although the number of turns was selected to get a turns ratio of 100 , to allow the 
transformer to be excited from a $230 \mathrm{~V}$ supply. The neutral connection to the HV winding was made at the outer layer and the core left floating at the high voltage. The LV winding thus shielded the HV winding for electric field coupling to grounds external to the device. This reduced corona from the windings.

To test the effectiveness of the resonant transformer, 10 capacitors of an inverted Marx impulse generator were connected in parallel to give a nominal load capacitance of $0.65 \mu \mathrm{F}$. This equated to an impedance of 4,900 ohms, which was almost equivalent to the transformer impedance for 9 layers, and corresponded to the tests undertaken on site with the resonant inductor. Consequently the transformer was tested in this configuration, not at the 10 layers designed for.

The low voltage winding was energised from a $230 \mathrm{~V}$ variac. The transformer showed linear behaviour through to rated high voltage. However, to get $23 \mathrm{kV}$ on the $\mathrm{HV}$ winding, $285 \mathrm{~V}$ was needed to be applied to the LV winding. This gave a voltage ratio of 81 , well below the rated value of 90 . The HV winding current was measured at 4.9A, equivalent to the Matahina stator and consistent with a load impedance of 4,700 ohms. The LV winding current was 55A. This gave an input volt-amperes of $15.7 \mathrm{kVA}$ for a load value of $113 \mathrm{kvar}$, or a gain of 7.2. The real power losses in the transformer were measured to be $3.5 \mathrm{~kW}$.

The loss in voltage ratio was considered to be due to the LV winding, which was $500 \mathrm{~mm}$ in length, not completely covering the $\mathrm{HV}$ winding, $720 \mathrm{~mm}$ in length. It was surmised that there was significant leakage flux in the $110 \mathrm{~mm}$ long regions between the end of the LV winding and the $\mathrm{HV}$ winding end.

This transformer cannot be operated on open circuit as the LV winding was not designed to take the high magnetising current under steady state conditions. The calculated open circuit current of $490 \mathrm{~A}$ would give rise to a current density of $39 \mathrm{~A} / \mathrm{mm} 2$, which would soon overheat the winding.

\section{TUNABLE RESONANT TRANSFORMER}

\subsection{Initial Design Considerations}

A request came to design a resonant inductor to test a $50 \mathrm{~Hz}, 13.8 \mathrm{kV}, 135 \mathrm{MVA}$ generator stator at $31.5 \mathrm{kV}$. The stator capacitance was estimated to be $1.083 \mu \mathrm{F}$. Given the time constraints for the initial on-site use of this device at the Manapouri underground power station, the use of an existing core was envisaged.
The design approach was to take the dimensions of the core, namely $175 \mathrm{~mm}$ diameter and $1200 \mathrm{~mm}$ length and weighing $217 \mathrm{~kg}$, and purchase an appropriate former on which the HV winding was wound. This formed an inductor with a winding length of $1000 \mathrm{~mm}$, chosen to allow a core overlap for suspension in a cradle. 8 layers of $1.8 \mathrm{~mm}$ diameter copper wire, weighing $64 \mathrm{~kg}$, gave a total of 4000 turns. This gave a voltage rating of approximately $8 \mathrm{~V}$ per turn and a maximum inter-layer voltage of about $8 \mathrm{kV}$. At the rated voltage of $31.5 \mathrm{kV}$, the design flux density was $1.55 \mathrm{~T}$ peak which would marginally push the silicon steel core into saturation. This was unavoidable as the critical design characteristic was to match the magnetising reactance to the nominal stator capacitive reactance of 2939 ohms. The rated current was $10.6 \mathrm{~A}$ to give a reactive power rating of $334 \mathrm{kvar}$, and a wire current density of $4.2 \mathrm{~A} / \mathrm{mm} 2$.

To turn this inductor into a resonant transformer, a LV winding was designed to be put over the $\mathrm{HV}$ winding. The design called for 1 layer and 50 turns for a nominal turns ratio of 80 . The predicted performance under load using an excitation voltage of $400 \mathrm{~V}$ was for a primary current of about 11A, as compared to an open circuit current of $860 \mathrm{~A}$.

\subsection{Practical Fabrication Considerations}

The design calculations were used as an estimate of the actual or as-built dimensions required for the device. Each layer of the $\mathrm{HV}$ winding was required to be insulated to withstand the voltage of a induced overvoltage test of $40 \mathrm{kV}$ for 3 minutes. This gave a maximum inter-layer voltage of $10 \mathrm{kV}$ when using 8 layers. Nomex-Mylar-Nomex (NMN) 373 was initially chosen as the insulation. This has a nominal thickness of $0.35 \mathrm{~mm}$. . A test sample of Nomex put between 2 layers of winding wire of 45 turns per layer, and using $100 \mathrm{~mm}$ overlap of the Nomex for creepage, indicated a withstand voltage of $20 \mathrm{kV}$ for 1 minute and a breakdown value of $25 \mathrm{kV}$ after 15 seconds. Two layers of the same material gave similar results. In both cases, highly visible arcing occurred at the winding sample ends, which ultimately caused burning and failure of the insulation.

In an attempt to suppress the corona, crepe Nomex was used to bind the windings. Unfortunately the crepe created air channels through which corona inception occurred, resulting in a similar breakdown performance to the cases without the crepe. To exclude air from the endwinding region of the sample, neutral cure RTV was squeezed into a channel between the winding wire and a barrier of crepe Nomex. After soaking the insulation 
at $15 \mathrm{kV}$ for 10 minutes, it failed after 1 minute at $20 \mathrm{kV}$. The application time of the voltage was thus shown to be important.

The primary insulation was changed to Nomex 3-14-3, which has a nominal thickness of $0.5 \mathrm{~mm}$. The wire was bound with fibreglass/polyester tape and the whole sample immersed in transformer oil to provide a non-air dielectric and hence suppress the endwinding corona. This combination withstood $15 \mathrm{kV}$ for 10 minutes, but failed at $20 \mathrm{kV}$ after 3 minutes. The use of oil posed a fabrication problem considered undesirable in this application. A final insulation test used Sylgard silicone elastomer in the endwinding regions. This was a 2 pot non-exothermic mix, poured between the Nomex layers and set using low temperature heat. The performance was similar to that for the sample immersed in oil. The breakdown value was deemed acceptable as the maximum electrical stress during the induced overvoltage test of about $10 \mathrm{kV}$ per layer of insulation was significantly less than this, and the application time was to be 3 minutes.

To allow a measure of flexibility in performance, 9 layers of $\mathrm{HV}$ winding were wound on the former. This weighed $72 \mathrm{~kg}$. Available wire allowed 3 layers per drum, so taps were made at layers 3 and 6 and also 7, 8, and 9 to allow tuning under test conditions.

In the fabrication of the actual winding, about $50 \mathrm{~mm}$ of the endwindings were bound with the fibreglass/polyester tape for mechanical strength. The nominal layer length was $920 \mathrm{~mm}$, although the turns were decreased each layer to allow a neat overlapping at the ends. Taps were brought out at right angles and insulated with 3 layers of heat shrink.

Before completing the insulation system for the device, the performance of the $\mathrm{HV}$ winding as a standalone inductor was evaluated. A relatively low voltage of $4 \mathrm{kV}$ (known to be safe with the endwings in air) was applied to 8 layers. The inductor showed a nearly constant reactance of $2850 \mathrm{ohms}$. As the actual value of magnetising reactance can be critical to the resonant performance, the core was slid partially out of the winding space. A displacement of $360 \mathrm{~mm}$ from the centre gave a reduced reactance of $1780 \mathrm{ohms}$. Thus the device was tuneable to a specific load by adjusting the position of the core.

To energise the low voltage winding, the only available regulator was rated for $230 \mathrm{~V}$ operation before saturating. Also, the only procurable wire that would allow full coverage of the HV winding was $7.1 \mathrm{~mm}$ by $3.55 \mathrm{~mm}$ rectangular aluminium. The $\mathrm{LV}$ winding was wound in 2 equal 32 turn sections, as 2 parallel conductors, side by side. This allowed the sections to be connected in either parallel or series to give nominal turns ratios of 141 and 71 to allow supply from either nominal $230 \mathrm{~V}$ or $400 \mathrm{~V}$ excitation. These windings added only $7 \mathrm{~kg}$ to-give a total metal weight of about $295 \mathrm{~kg}$. The completed resonant transformer is shown in Figure 2.

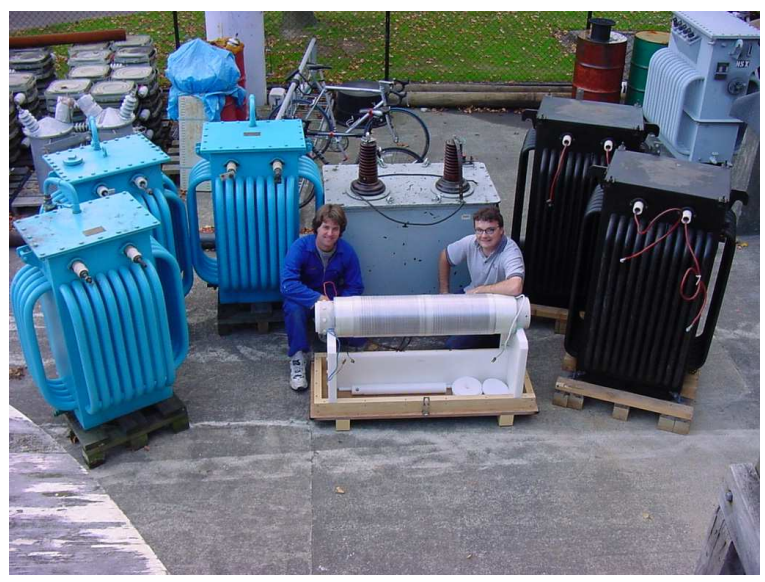

Fig. 2 Manapouri resonant transformer (front) along side equipment previously used at other power stations (back)

As a result of tests on the Matahina resonant transformer conversion, the device was to be operated with the core floating at high voltage and the neutral end of the HV winding, next to the core. It was discovered that by doing so, taps 7 and 8 could not be used as layers 8 and 9, and layer 9 respectively floated, giving rise to corona. In future designs, the taps should be on the inner layers. However, this loss of flexibility was offset by the LV winding effectively being an shield, attenuating electric fields external to the device. This removes the necessity to elevate the resonant transformer significantly above the ground.

\subsection{Performance Testing}

All 9 layers were now connected to form the HV winding. A dummy $5 \mathrm{kV}$ rated capacitance of $1 \mu \mathrm{F}$, corresponding to $3183 \mathrm{ohms}$, was placed across the $\mathrm{HV}$ winding as a load. With the LV windings in parallel, the core was placed $400 \mathrm{~mm}$ off centre to give a measured magnetising reactance of 3070 ohms. Unfortunately the asymmetry of the core relative to the windings gave rise to significant circulating currents which effectively prevented operation. A preliminary test gave a measured turns ratio of 135 , however some $80 \mathrm{~A}$ of current circulated in the $\mathrm{LV}$ windings for less than $10 \mathrm{~V}$ of applied voltage. 
Using only one LV winding reduced the current dramatically, however the turns ratio dropped to about 100 , with a $50 \mathrm{~V}$ applied voltage giving rise to $5 \mathrm{kV}$ on the HV winding. Placing the two LV windings in series reduced the turns ratio to 78 . Centralising the core with this arrangement maintained the ratio but changed the resonant point such that the supply VA increased.

Having proved the viability of the transformer operation, the LV turns were reduced to 31 . The end windings of the completed unit were then filled with Sylgard. This allowed full voltage tests to be undertaken. Eighteen capacitors from the inverted Marx impulse generator were connected in parallel to simulate the actual Manapouri generator stator. The resonant transformer core was set at $415 \mathrm{~mm}$ off centre to the windings. In an induced over-voltage test, the $\mathrm{HV}$ winding was energised to $25 \mathrm{kV}$. The open circuit voltage on the LV windings was $345 \mathrm{~V}$ to give a turns ratio of 72 , only just below the rated value of 73 . The capacitive reactance was measured to be about 2770 ohms, and the magnetising reactance of the transformer was 2530 ohms

With the load adjusted to $1.01 \mu \mathrm{F}$ or about $3200 \mathrm{ohms}$, the core was displaced by $300 \mathrm{~mm}$, and the $\mathrm{HV}$ winding energised to $32 \mathrm{kV}$. At this voltage, the $\mathrm{LV}$ winding voltage was $450 \mathrm{~V}$ to give a turns ratio of 71 . There was almost perfect matching of the magnetising reactance with the capacitor. This was the maximum voltage that could be obtained without the core saturating.

The load capacitance was reduced to $0.56 \mu \mathrm{F}$ or 5680 ohms. With the core centralised, the magnetising reactance was measured to be very similar at low voltages, however when the full $40 \mathrm{kV}$ overvoltage was applied for 3 minutes this dropped to about $5000 \mathrm{ohms}$, indicating some measure of saturation.

The next phase was to test the resonant transformer when it was energised from a low voltage source. To better match the ratio of the windings, a single turn was removed from each of the LV windings. With these connected in series, an excitation of $445 \mathrm{~V}$ gave the required $31.5 \mathrm{kV}$ on the secondary, a turns ratio of 71 as against the nominal value of 73 . With the $\mathrm{LV}$ windings connected in series, the $31.5 \mathrm{kV}$ voltage on the $\mathrm{HV}$ winding was achieved with $223 \mathrm{~V}$ applied. The turns ratio was 141, as compared to the nominal value of 146 . As a final test, $0.98 \mu \mathrm{F}$ of capacitance was connected to the $\mathrm{HV}$ winding. With the core displaced $350 \mathrm{~mm}$ from the centre, a $400 \mathrm{~V}$ supply gave $28.6 \mathrm{kV}$ on the $\mathrm{HV}$. This is the final acceptance voltage level for the generator stator.

\subsection{Client Acceptance Tests}

The performance of the resonant transformer was demonstrated to the client through three tests. With the core centralised, the induced overvoltage test on the HV winding was conducted at $40 \mathrm{kV}$ for 3 minutes, charging a capacitance of $0.57 \mu \mathrm{F}$. The winding current was 8.7A. It was observed that the core heating was uneven during this test. Measurements indicated that the core centre was relatively cool at about $30^{\circ} \mathrm{C}$ as compared to an ambient temperature of $20^{\circ} \mathrm{C}$. The outside of the core perpendicular to the laminations was of a similar temperature. However, the outside of the core parallel with the laminations was up at temperatures of the order of $60-70^{\circ} \mathrm{C}$. These higher temperatures are probably due a combination of factors. There is radial flux at the core ends that induces emfs and hence eddy currents in the laminations. There are also shorter paths for eddy currents due to the axial flux circulating in these laminations that gives rise to a smaller path resistance. For the same induced voltage, the eddy current power loss and hence heating increases. It may also indicate that there are uneven eddy current distributions in the core laminations, and hence in the flux density, due to the different widths of the cut laminations. This may be a factor in the core saturating at a lower applied voltage than was expected. It may also indicate that laminations do not give rise to even flux density throughout the core.

The second acceptance test showed that the transformer could be excited from a nominal $230 \mathrm{~V}$ supply, and allowed a number of stator bars to be tested during the installation phase. For a $0.57 \mu \mathrm{F}$ load, the $\mathrm{LV}$ winding operated at $224 \mathrm{~V}$ and $47 \mathrm{~A}$. The $\mathrm{HV}$ winding voltage was the required stator bar interim test voltage of $31.5 \mathrm{kV}$. The load current was 5.4A. The LV winding rating was about $11 \mathrm{kVA}$, as compared to the compensation value of $170 \mathrm{kvar}$ on the $\mathrm{HV}$ winding.

The final acceptance test was the supply of $28.6 \mathrm{kV}$ to a capacitor of $1.04 \mu \mathrm{F}$, being essentially the design value of the completed stator. The core was displaced at $350 \mathrm{~mm}$ from the centre. The secondary current was $9.3 \mathrm{~A}$ to give a rating of $267 \mathrm{kvar}$. The primary was excited to $402 \mathrm{~V}$ and $42 \mathrm{~A}$ to give a power rating of $17 \mathrm{kVA}$. The VA ratio was thus 16 .

Having passed these tests, the resonant transformer has since successfully been used on site at the Manapouri power station to test the initial batch of installed generator stator bars. The test voltage was $36.5 \mathrm{kV}$ and the capacitance of the installed stator bars was measured at $0.49 \mu \mathrm{F}$. During the test, a flashover occurred on the stator. The resonant transformer 
showed no damage from this full circuit condition at high voltage, proving the electrical and mechanical integrity of the winding system.

In a follow up test, the Matahina resonant transformer was reinsulated to operate $32 \mathrm{kV}$ and inserted as an inductor in parallel with the Manapouri resonant transformer. Each complete phase of the generator stator of $1.06 \mu \mathrm{F}$ was tested. The stator current was $10.6 \mathrm{~A}$ to give a reactive power of $339 \mathrm{kvar}$. The Matahina and Manapouri resonant transformers had currents of 4.0A and 7.1A respectively. The primary was excited at $443 \mathrm{~V}$ and took $70 \mathrm{~A}$, to give a VA rating of $31 \mathrm{kVA}$ and an output to supply VA ratio of 11 .

\section{CONCLUSIONS}

Generator stators require high voltage testing of their insulation as part of their acceptance before being put into service. Traditionally this has involved the application of a high dc voltage. However, more and more utility owners are calling for over-voltage acceptance tests to be made at mains frequency. Under ac conditions, the amount of current required by the insulation capacitance may not be insignificant. To supply this current directly from a power supply can involve a capacity greater than what is available from local services, such that dedicated test units with their own generator sets may be necessary. These can be physically very large and heavy, with consequent high test costs.

An alternative test apparatus has been designed around a partial core transformer concept. The transformer has laminated core material only in the space enclosed by the windings. There are no limbs and yokes as found in conventional full core transformers. One of the characteristics of these transformers is that they have relatively low magnetising reactance. Through judicious design, this reactance has been matched to generator stator capacitance such that the reactive current of the insulation is provided by the transformer magnetisation. This is essentially setting up a parallel resonance between these two components. This means that the supply only has to provide the real power losses of the transformer and in practice any mismatch between the magnetisation current and the stator capacitance. The primary winding can thus be downsized to conduct only this supply current.

To test the resonant concept in practise, a high voltage inductor was designed and used in the testing of a generator at a New Zealand power station, Matahina. It supplied $115 \mathrm{kvar}$ of reactive power compensation at $23 \mathrm{kV}$. The inductor weighed $120 \mathrm{~kg}$. The inductor was subsequently modified by the addition of a low voltage primary. A laboratory test, with an appropriate capacitive load, showed that the required high voltage of $23 \mathrm{kV}$ could be obtained from energising the primary at $285 \mathrm{~V}$ at $60 \mathrm{~A}$ or at a rating of about $1 / 7$ th the load.

A further resonant transformer was then designed for a $334 \mathrm{kvar}$ capacitor load to test Manapouri power station generator stators at $31.5 \mathrm{kV}$. This transformer was subjected to an induced overvoltage test of $40 \mathrm{kV}$ for 3 minutes, before demonstrating compensation of $0.57 \mu \mathrm{F}$ load from a $230 \mathrm{~V}$ supply. It also provided $28.6 \mathrm{kV}$ to a $1.04 \mu \mathrm{F}$ load, essentially being the design value of the actual generator stator. It was excited from a nominal $400 \mathrm{~V}$ supply, and gave a gain of 16 in VA. The transformer has a finished weight of approximately 300 $\mathrm{kg}$. On site, the resonant transformer was used to supply $36.5 \mathrm{kV}$ to the initial batch of installed stator bars at $0.49 \mu \mathrm{F}$. This is the equal to a capacitive load of $205 \mathrm{kvar}$. It also withstood a stator flashover proving the electrical and mechanical integrity under short circuit.

In a follow up test, the Matahina resonant transformer was reinsulated to operate $32 \mathrm{kV}$ and inserted as an inductor in parallel with the Manapouri resonant transformer. Each complete phase of the generator stator of $1.06 \mu \mathrm{F}$ was tested. The output to supply VA ratio was 11 .

\section{REFERENCES}

[1] Hipotronics, www.hipotronics.com

[2] Agea-kull, www.agea-kull.ch

[3] Liew M.C., and Bodger, P.S., "Partial core transformer design using reverse modelling techniques", IEE Proc. Electric Power Applications, v148, no. 6, November 2001, pp. 513-519.

[4] Liew, M.C. and Bodger, P.S., "Applying a reverse design modelling technique to partial core transformers", J. Electrical and Electronics Engineering, Australia, v22, n1, 2002, pp. 85-92. 